\title{
Article
}

\section{When the body makes its presence felt: Somatic-informed movement practice as an integral part of the hospital care team}

\author{
Collinson, Penny Sybil
}

Available at http://clok.uclan.ac.uk/35590/

Collinson, Penny Sybil ORCID: 0000-0002-2869-7132 (2020) When the body makes its presence felt: Somatic-informed movement practice as an integral part of the hospital care team. Journal of Dance \& Somatic Practices, 12 (2). pp. 289-302. ISSN 1757-1871

It is advisable to refer to the publisher's version if you intend to cite from the work. http://dx.doi.org/10.1386/jdsp_00029_1

For more information about UCLan's research in this area go to http://www.uclan.ac.uk/researchgroups/ and search for <name of research Group>.

For information about Research generally at UCLan please go to http://www.uclan.ac.uk/research/

All outputs in CLoK are protected by Intellectual Property Rights law, including Copyright law. Copyright, IPR and Moral Rights for the works on this site are retained by the individual authors and/or other copyright owners. Terms and conditions for use of this material are defined in the policies page.

\section{CLoK}

Central Lancashire online Knowledge www.clok.uclan.ac.uk

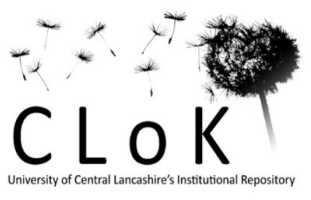


When body makes its presence felt: somatic-informed movement practice as an integral part of the hospital care team

\section{Penny Collinson}

\section{University of Central Lancashire}

\section{December 2020}

\section{Abstract}

This article addresses the nature of somatic-informed movement practice (SIMPi) taking place in hospitals, as a participatory art form. It focuses on data from a report which collates the scope of practice, working patterns and procedures of somaticinformed movement practitioners in the UK (Collinson and Herd, 2020), and specifically the views of the six practitioners interviewed. The article will firstly identify key principles and values underpinning SIMP exploring ways in which it might support people with illness. This is followed by a description of the aims and function of the report and data which enables us to see how SIMP cultivates embodied relational awareness through a 'co-creative' process, and concludes by addressing why creativity and presence can support people who may have lost trust and connection with their bodies through illness. The article acknowledges the challenge of placing embodied arts practice (such as SIMP) in a medical paradigm and includes recommendations for ways forward.

\section{Keywords}


Somatic-informed; movement; participatory arts practice; hospitals; cocreation.

\section{Somatic-informed movement practice (SIMP)}

SIMP is a relatively small and distinct area of dance practice, foregrounding an approach to the body and movement that uses improvisation, sensory awareness, imagination and touch. SIMP shares some of the practical identifiers/components of the wider field of somatic movement education/therapy, including:

- the involvement of spontaneous and improvised activities and responses

- consciousness towards the sensory and felt-sense of the body

- involvement of the imagination

- an awareness to the presence of emotion, anatomy, affect, memory and dream

- the regulatory support of the autonomic nervous system

These components outlined above can be explored through numerous creative methods and techniques involving movement, touch, voice/sound work and in some cases arts practices.

At the very heart of SIMP lies trust in our bodies as intelligent, self-aware and adaptive (Hanna 1976). These attributes become known through the seemingly simplest of activities- breathing, touching and being touched, moving and stillness, and it is in noticing and tracking our experiences of these that we discover their effects. An interest and curiosity in the process of sensing and/or moving with internal awareness, develops a sensitivity toward our living bodies, and we can become more attuned to our physical, physiological, cognitive and emotional rhythms and responses. Indeed, many of the pioneers of somatic practice- Bainbridge-Cohen, Feldenkrais, Alexander, Starks Whitehouse, Halprin, developed their practices as a response to a personal illness or 
condition (Johnson 1995, 1992, Mullan 2014). Martha Eddy writes that in 'paying attention to the body, one is paying attention to the mind. [...] This "mind of the body" has the ability to sense itself, interpret sensations as perceptions and then form thoughts, feelings, associations, and imagery from these perceptions' (2016: 6). Therefore, awakening to our bodies and getting a feel for our own particular 'nature', as Eddy suggests, requires an approach which values the subjective dimension of movement as it is experienced by the individual.

Dance artists are often skilled in ways which support others to sense their bodies, and observe the tones and smallest shifts and changes, from which movement may be expressed. In SIMP, dance artists believe in the relational and 'co-creative' aspects of facilitation as central to, and as guiding the process between themselves and their participant. They see co-creative practice as an emergent process, fluid, spontaneous and underlined by trust- trust in their embodied wisdom to guide the process, trust in the potency of relationship to strengthen a person's resources (Tufnell 2017: 95). Miranda Tufnell points out,

This is not 'dance' in the conventional sense, but rather communication through movement and the body. Somatic approaches train a bodily listening that is highly sensitive to these bodily movement tones and patterns. Developing a person's awareness of these subtle inner movements relaxes and stimulates blood flow, bringing about a settling and whole body reorganisation (2017: 105). 
Tufnell's 'settling' and 'body reorganisation', creates the potential to feel differently, a transformation from one physiological state to another, through movement which can awaken the senses and our imagination, so as to bring new possibilities.

\section{Why might embodiment be important to health and wellbeing?}

Through pathology, body makes its presence felt. Many people are not aware of their bodies until something is going wrong and they no-longer look, move and feel as they normally do. With illness all aspects of us are affected, with the potential to lead to uncertainty, anxiety and distrust in our bodies, often resulting in physical immobility, cognitive confusion and other conditions, particularly for the elderly. In illness, whether it be short-term or chronic, we can lose connection to what we know and value in our lives. Phenomenologist Havi Carel, writes of 'bodily certainty' (2013: 6), as being a bodily feeling of ability (bodily feelings of being comfortable, of being in control of one's body, having a sense of familiarity and trust of one's body). The opposite of this says Carel, is 'bodily doubt' which occurs through a disruption or breakdown to this belief. Because illness can give rise to 'an experience of unreality, estrangement and detachment' (Carel 2013:6), reaching out for support through activities that can ground us and rebuild a relationship to our body can rekindle this bodily certainty. In the following descriptive account, Cai Tomos reflects on an encounter with a patient in Chelsea \& Westminster Hospital during a project entitled, 'Meeting Places':

$P$ is sitting looking through the window, he speaks of his leg which is infected and he is unable to walk. $P$ is very anxious and fearful of what the future might hold. I suggest that we do some work on the breath and the feeling of connection to his leg. I explain about the building of neural pathways through movement and encourage him to do what feels right. As we work together $P$ 
begins to close his eyes and slowly move his leg a little. I asked him what it feels like, and he speaks of his leg being like a frozen lake. I gently ask if I can place my hand on or near his leg. The next 5 or 10 minutes are based on listening to $P$ begin to describe and expand on his perception of his injured leg. I ask questions to encourage the dialogue. Slowly he begins to describe a thawing of this frozen lake and through this use of imagination and metaphor P's perception of his injury begins to broaden and with that his confidence. That afternoon P tells me he feels ready to work with the OT's [Occupational Therapist] to begin to try walking. I hear back from the OT that something has shifted from this session that allowed $P$ the confidence to engage differently and perhaps with a little more confidence in his recovery.

(Tomos, 13 March 2017, personal correspondence)

Movement processes which support us to feel our body's presence and experience wellness amidst illness and discomfort, such as we see above, hold the potential for subtle and substantial impact on a patient's rehabilitation, affecting change in mood, motivation, pain relief and quality of life (APPGAHW 2017; Connolly \& Redding 2010; Dowler 2013a, 2013b, 2016; Jarrett 2019; Gersten Roberts 2017; Payne 2017; Pereira-Stubbs 2017; Tufnell 2017). These effects are widely acknowledged in therapeutic and complementary health settings, though less known and developed in hospital settings.

Tomos, a dancer, expressive arts therapist and Somatic Experiencing practitioner, describes his work with patients as having four intentions: supporting social engagement, developing resources, physical mobility, and a sense of narrative (the personal story of health for the patient). He speaks of seeing some patients in a 'freeze' modality, where the onset of illness has brought about a loss of coherence of the 'whole' and within that a loss of the 'inner self or soul' (Tomos, 16 January 2020, interview). 
His one-on-one bedside work aims to remap sensation to the places or aspects of a person that have been forgotten, involving their imagination. He shares, 'for those who can't move, instead they tell me somewhere they love, a place. "What do you notice about that place in your body? Can you imagine walking in that place? What's the ground like?"' (Tomos, 28 March 2018, interview). He further reflects that when patients are feeling incoherent, many look for certainty and support, and he sees his role on the ward being to hold steady with a 'knowing without knowing' (Tomos, 28 March 2018, interview). The aim is to build resources in patients who have lost faith in their bodies, with creative approaches that can support them to regain connection to their lifeworld, a form of 'seeking out the particular and personal, and in so doing, strengthening what is well' (Tufnell 2017: 104). Tufnell's emphasis on wellness amidst illness is an implicit motivation for artists in hospitals.

The Creative Health Report, by the All Party Parliamentary Group for Arts Health \& Wellbeing (APPGAHW), states that 'as a by-product of the creative process, dance stimulate[s] an expanded sense of self and of community, providing a set of tools for enhancing everyday life and navigating the ageing process' (2017: 12). The presence of an embodied approach in the clinical, medicalized setting of a hospital offers a paradigm which can connect a person to who they are beyond their illness, and offer simple resources to support the clinical interventions they are receiving (Dowler 2013a, 2013b, 2016; Tufnell 2000, 2017).

\section{Background to the Report}

In 2020, Herd and I published a report which identifies the work of dance and somatic movement practitioners specifically within NHS hospital settings. The rationale for this research grew out of debates between practitioners who reported difficulties in 
establishing and sustaining opportunities in hospitals. Concerns largely pointed to a lack of adequate dialogue between healthcare professionals, commissioners and themselves, 'where ideas about the body can be widely divergent' (Dowler 2013b: 9), and where there is little understanding of the skills practitioners might bring to the wards. Dance practitioners wanted to know more about where and how the work is taking place, so that amidst the goals of hospital care, regulated hospital policies, and tight funding budgets, opportunities might evolve. A function of the report is to enable practitioners to see their work in the context of others', fostering greater communication with peers, and reducing the sense of isolation which many can feel.

The report gathers the views and experiences of practitioners, collating data on the range or scope of practice, and their working patterns and procedures. It includes findings from:

- An anonymous online survey (of 47 respondents) undertaken in the first phase of this research (March-July 2017) which targeted dance and somatic practitioners through academic and arts networks, websites and dance agencies.

- Interviews with six leading practitioners working in the field which took place between May 2017-March 2020: Lisa Dowler (Liverpool/France), Stella Howard (London), Lucinda Jarrett (Oxford/London), Filipa Pereira-Stubbs (Cambridge), Susie Tate (Northumberland /Cumbria), Cai Tomos (London/Wales).

The report is organised into 4 subheadings of research with key themes emerging from these.

1. How do practitioners identify their role in hospitals?

What is their scope of practice? 
What is their remit?

2. Where in the UK are practitioners based?

On which wards is the work happening?

3. How are practitioners contracted /what is their employment status?

How is the work evaluated and why?

4. In which ways do practitioners find support for their professional work?

This article focuses on data from question 1 of the report covering themes regarding working remits and the application of practices. Emerging from the interviews is a focus on co-creation, how the artists talk about it, how they understand their practice, and what it offers the field.

\section{SIMP on the ward}

The report gathers data from practitioners who have been working in hospitals since 1998. We see they are trained in different disciplines- dance, somatics, bodywork, psychotherapy and expressive arts. In this setting they refer to their role in a variety of ways, some give multiple answers, but the most common title is 'Dance/Movement Artist' (followed by 'Facilitator' and 'Dancer'). This may be because it emphasizes the art of their practice allowing for potential freedom and diversity in working methods and outcomes- performative and participatory. Those who have been working for some years however acknowledge the vulnerability of their role as 'artist' because it isn't seen or understood sufficiently within the ward teams. One practitioner talks of being perceived as an 'entertainer' and hopes that her work can be viewed as both fun and playful whilst also being recognised as beneficial and transformative.

The report gathers information on the working remits of practitioners- the reasons they were brought onto the wards (Illustration 1), and the practices, approaches and 
methods practitioners use with patients (Illustration 2), predominantly, improvisation, somatic movement practices and touch/bodywork.

Illustration 1

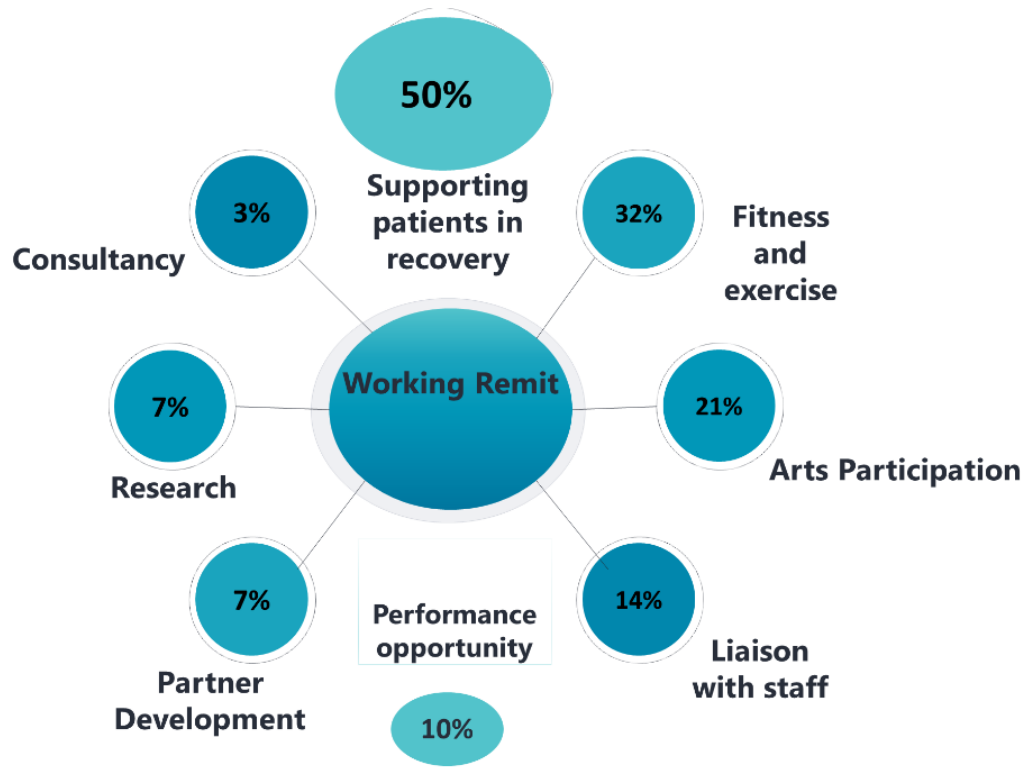

Illustration 2

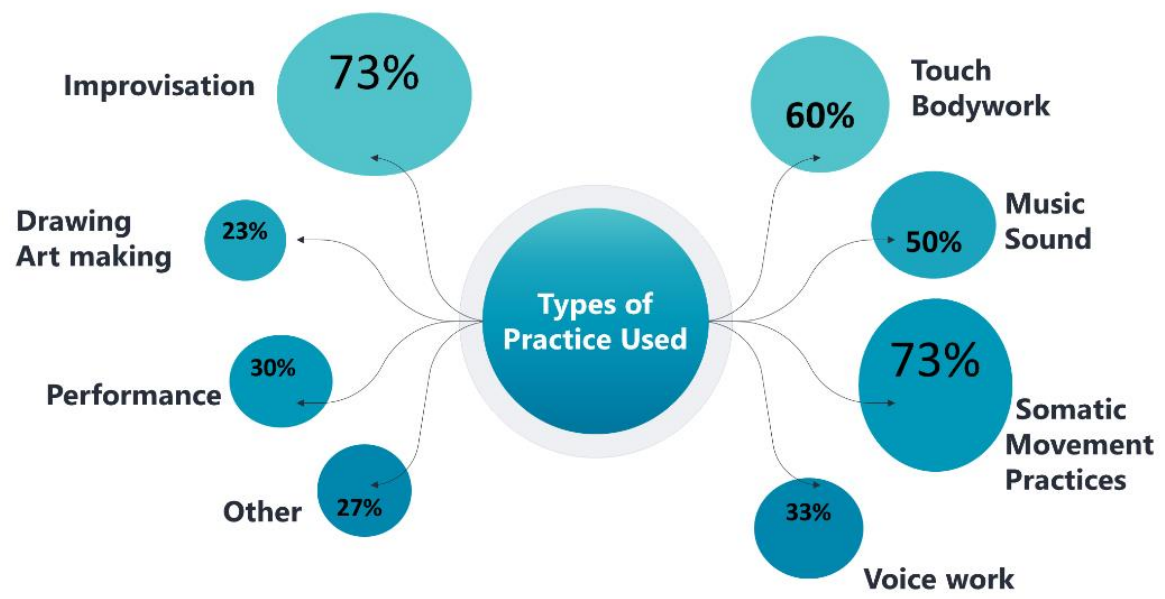




\section{Co-creative practice}

The majority of the practical approaches named above are facilitated in ways which practitioners call co-creative and they involve an unfolding sensing-moving dialogue between themselves and their participant. Identifying the "steps" (or direction) their practices take, and the effects or "outcomes" produced is useful in order to grow and sustain the field. Intrinsic outcomes which support personal, social and emotional development in the patient, include qualities such as self-care, expression, resilience, communication, social engagement and personal motivation. How this happens will be unique to each interaction. When Stella Howard, an artist-in-residence in Great Ormond Street Hospital (GOSH), was asked what lies at the heart of her approach on the ward, she speaks of 'finding a language to work with a child, their body and their needs for that day' (Howard, 25 February 2020, interview). Her artistic starting place of "hands" invites a child to respond as they do in that moment. "I go in, I meet, I encourage...there's a moment of transfer so they guide me with whatever movement that might be. The outcome will be different with each child I meet'. Stella refers to this process as co-facilitation or co-creation and explains it simply to the child or parents as an approach which 'is very gentle, taken from you or me and however you want to move'. It will sometimes start with ideas around breath, filling their lungs and expanding their body, 'floating, reaching...or I start a game of mirroring with fingers, and see where that leads...a subtle finger movement, or a confident gesture, in that moment I'm following the child's choices, but also intently sensing their energy, physical choices, movement range, and potential range in our relationship together'

(Howard, 25 February 2020, interview). All of the practice is improvised and dependent on the person she is working with. 
Howard particularly likes working with babies or people with severe movement complexities, trusting that dance can access them. In the interview, she describes a 'duet' with an 18-month old baby boy who she worked with over 6 weeks. He was extremely small for his age and displayed very few movement responses: ' $/$ started with touch work and encouraged a little sensation through his body, this developed to squeezes, moving and encouraging his movement. He didn't have much movement at all. I had a small hand solo which I performed around the child with calming music. He started to follow my hands with his eyes and by week 4 he was reaching for my hands. I was doing a full improvisation with the baby, with him moving and surprisingly pushing to lift up his hips to join in' (Howard, 25 February 2020, interview). The delighted foster carer brought in a nurse to see what was happening because the baby was moving more than he had shown possible before. It is Howard's hope, that the carer is now able to trust the boy has greater movement capacity, and that she will feel more confident to support his movement in ways herself.

In Howard's description above, we see that movement/touch or verbal cues are informed by her own sensory feedback-loop. She is present and attuned to her body. Howard's connection to her sensory-imaginative experience, as it arises spontaneously, guides the moving process so that both her own and her partner's subjective experiences can be 'heard'. Dowler also speaks of being guided by her own embodiment in her touch-based work, picking up on the quality and tone of the muscle or fluid tissues in a patient's body, sensing micro-movements, and listening/watching for shifts in sound, breath or eye contact. Their bodily 'knowledge' informs the cocreative process, which in Howard's case brings the baby into a non-verbal moving 'conversation'. 
The principles of co-creation can be found in other disciplines too, for example cocreation aligns with the idea of intersubjectivity in psychotherapy, '[i]ntersubjectivity refers to the synthesis of two people sharing an experience together. Each person brings [...] his or her own phenomenological experience... [out of which] a new psychological synthesis occurs' (Erskine 2018: xxxii, xxxiii). Similarly, in SIMP, the practitioner and client/patient will follow a process which will be unique to each relationship. Tufnell writes of bodily empathy underpinning this work which requires the practitioner to hold dual awareness, 'to sense and feel with another, yet also to stay connected to self and the surroundings' (2017: 108-9). She adds that the quality and spaciousness of our own presence and attention profoundly affects what happens with another person, and that 'through listening and offering a creative and receptive space, a person's own resources are able to surface' (2017: 110).

It is not essential for patients to understand the process of co-creation, but rather that the practitioner guides /is awake to the creative potential of the encounter, aware of the affective responses taking place in his/her client, while holding a safe containment of space and time.

In body-based creative practices strong feelings and emotions can be felt, expressed and grounded, channelled into the movement (the song, the music) or delicately spoken through story or poem. Practitioners are not teaching or directing in the hospital but facilitating the participants towards their embodied experience in ways which offer both freedom and containment- freedom to release their imagination and feeling-sense, and containment to integrate and share what they find. Being present to their own subjective experience reorients patients towards the emergent nature of 
their living bodies and begins a process by which personal agency and self-authority can grow.

Tomos describes being with patients at their bedsides, and his intention to 'give space for relaxation, calm, and to be with the body in a different way' (Tomos, 28 March 2018, interview). He arrives with a patient, quietly offering spaciousness, he feels his way to start a conversation which could guide them towards more bodily presence and ease, 'if I have as much clarity around my own lived experience as it's happening and the space in that, then I think people sniff it out... there's a space that becomes available...[s]omething happened within that time frame [20-25 minutes].... and that started to establish itself more clearly as the project continued, perhaps, as I became more familiar with the possible rhythm...... didn't have to rush between patients there was no pressure on me... there was a different feeling of being with people.' (Tomos, 28 March 2018, interview). Patients reflected their experiences back to him as a 'time of relaxation, and a change of breath, or a relief from what they had been through.' (Tomos, 28 March 2018, interview)

Like Tomos, Dowler's work at Alder Hey Children's Hospital Trust, includes a one-onone touch-based participatory practice. Her work with children takes place on the Cardiac and Neuro Rehabilitation Wards, where patients are undergoing long-term rehabilitation, and her practice aims to bring relief, ease, and playfulness to the child. Dowler describes the approach of 'engaging through the small, fragile, often barely perceptible movements that give expression to a child's world' (Dowler in Tufnell 2017: 97). The interactions, like the ones described by Tomos, require a slow pace, with the capacity to tune in, feel the tone and receptivity of the child's body, and support them to express themselves and find more bodily function. Lucinda Jarrett gives a further 
description of one-on-one work with older patients on the Dementia Care, and Neuro Rehabilitation Wards, specifically working with patients who have motor neurone disease and who are in stroke rehabilitation.

The patient chooses a track of music on the iPad, I start with touch to help to reconnect to body, I start slowly and carefully, always seeking permission... "where in your body would you like a hand?" It's usually a part which feels tense... finding breath, space to joints, embodied anatomy... I take people to different parts, shoulder, spine, limbs [Inviting them to] move from there... "what does it take to find movement there?"

(Jarrett, 4 May 2017, interview)

We see themes of group support, care and companionship in Jarrett's work, which she says is helping people 'connect to their bodies ... a place to be themselves' and 'to remember who they are... where movement can release the imagination which has become silenced through illness... so that patients aren't bed no. 53 but instead are the person who loves to dance salsa in their kitchen or the person who went to Cuba on holiday.' (Jarrett, 4 May 2017, interview). Jarrett's focus on the body as 'a place to be themselves' is echoed by Filipa Pereira-Stubbs, who describes her work as movement classes which help people 'remap their awareness of their body landscape' with a focus on 'what we can do, rather than on symptoms and what we can't do' (Pereira-Stubbs, 4 March 2020, interview). The underlying pedagogy of practice is to invite, encourage and support people to respond in their own way, improvising and making choices for themselves and with others.

\section{Social benefits of SIMP}


While co-creative practice happens with this group/demographic, group work has other social benefits. Susie Tate remarked on the levels of boredom for patients, particularly on the ward for older adults, where her remit is to create time for them to come together to explore, create, socialise and take part in exercise that can support their physiotherapy programmes.

All the practitioners emphasised the importance of companionship and interaction in rehabilitation, starting at the first point of contact between themselves and the patients. Pereira-Stubbs speaks of offering eye contact, perhaps a handshake, to clearly introduce herself and what they will be doing. She makes a point of taking patients to the windows and inviting them to share what they see- the colours, movement, dynamics of the landscape and weather, in doing so bringing the outside in, encouraging reflections and starting discussions. This is followed by time to gradually 'warm-up' and awaken to bodily sensation and movements using touch, voice and movement often accompanied by music or the use of objects. The intention of these aspects of a session is to gain body confidence, whilst supporting strength and balance. Movement that arises out of stories and imagination are also key characteristics of SIMP, allowing a person to respond spontaneously and intuitively and rekindle trust in their body. These activities are vital for self-care within the medical environment where patients are confined to beds, where movement is restricted, and care often requires painful intervention.

Howard reiterates the power of group work when describing the sessions she runs with adults who have brain injuries. The intention behind these sessions is to gain strength and balance and she approaches the sessions as 'a creative learning journey where one person sees an aesthetic moving experience in another' (Howard, 25 February 
2020, interview). There is often acknowledgment and valuing in the group for each other's progress. Howard suggests, 'the arts in this way offer an aesthetic artistic appreciation, all of which are as important as stabilising and balance, and the mechanics of movement...the arts offer people a chance to be in the experience of movement' (Howard, 25 February 2020, interview).

A further iteration of the social dimension of group work is in Jarrett's focus on performance. An aim of her company, Rosetta Life, is to initiate collaborative performance events that challenge the stigma of life lived with disability and illness. Over a twelve-week cycle, she and her team (of artists, healthcare assistants, and volunteers) run group sessions combining movement with song-making, and storytelling, which are composed through improvisation and lead to performance. The approach responds to different movement and speech needs offering ways in that places a patient's agency as central to the creative encounter' (Jarrett, 4 May 2017, interview). Supporting people as they adapt to the changes brought on by illness, Jarrett emphasises that 'making the performance enables people to work towards something [...] value [themselves] and others, [it is] a mark of achievement. [W]e are a 'company' for an hour and a half, that's really important. [...] a company is a way of building a community' (Jarrett, 4 May 2017, interview).

\section{Further thoughts}

The examples of group and co-creative one-on-one work above could be viewed as 'soft skills' producing 'soft outcomes', because of their focus on the personal and interpersonal, and relating to self/individual progress. Hospitals are under great pressure to get people better and discharge them and are often concerned with hard outcomes which rarely capture the effects of embodied practice. Small Things Dance 
Collective (Dowler, 2016, 2013b), and Rosetta Life (Jarrett 2019), are useful and encouraging exceptions to this, undertaking research using a mixed methods quantitative and qualitative phenomenological approach which includes peoples' lived experience, and demonstrates the methods and approaches they use.

The report and other anecdotal evidence show that there is growth of this work in the UK. However, whilst it has developed organically, with talented and committed practitioners aligning with open-minded and supportive commissioners, it remains disparate and inconsistent with many regions having no access to this kind of work. Part of the inconsistency of provision seen in the report may be explained by how hospitals value dance/movement practice.

In her 2013 article, Dowler asks how do we create a case whereby dance is not seen as adjunctive to healthcare but an essential part of it (2013a), and whilst this may take some time to achieve, it is clear that a process is already underway. As an advocate for embodied practice in hospitals I believe this work needs to be nurtured, strategically developed, and have greater visibility. Key to this are documentation, archiving, research and dissemination. I recommend practitioners engage in the following ways:

1. Develop methods for documenting practice, which includes capturing the lived experiences of patients, so as to enable evaluation.

2. Establish the effects and benefits for healthcare staff working with dance artists/somatic practitioners exploring further how they might work together; and in which ways embodiment might support healthcare staff professionally.

3. Continue evidencing the effects of practice through research; phenomenological studies into patient experience of somatic-informed movement practice in relation to personhood, wellbeing and relationship to 
illness are especially useful, as is research in pain relief and respiratory support. Academics and practitioners work in partnership with organisations, such as MIND, the Wellcome Trust, and/or directly with hospitals, to develop practice through qualitative case study research.

4. Artist/practitioners pursue funding opportunities through the NHS, Charities and Arts Councils.

5. Establish financial provision for a UK network which will advocate for the field, and offer support for practitioners including professional training opportunities, and developing peer support through training, mentoring, and supervision.

Existing health and social care literature recognises the importance of embodimentwhat Draper defines as the experience of living in and through our bodies (2014:2236) and redressing the out of balance perspective that seems to favour viewing the body as object (Draper 2014; WHO 2015, 2013). Draper et al, want to bring bodies back into the heart of nursing care, and for embodiment in nursing practice and healthcare education to be more understood (Bruyneel 2019; Dahlberg, Todres, \& Galvin 2009; Draper 2014; Galvin \& Todres 2013; Sakalys 2006). Dr lona Heath, speaks of seeing the 'person' not the 'patient', and of the need for health practitioners to develop receptivity, she warns against 'taking refuge in the sterile attitude of the spectator' rather 'listening and noticing', and 'being present' (2012: 244-245).

From a phenomenological perspective, illness splits apart the biological and the lived body (Carel 2008, 2012), and trust in the body becomes fragile, disrupted. Somaticinformed movement practices can reduce the gap between body-object and bodysubject with the potential to bring a greater sense of coherence and holism to bodies 
which feel broken. We see this in Tomos's reflection of being with 'E', and where imagination, memory and movement seem to call them back to their bodies:

$E$ is in the butterfly room. He is at the end of his life in the last stages of respiratory failure. I introduce myself and he begins to speak about his physicality- the physicality of his life, his love of sport, his love of fear, jumping from cliffs, skiing in Italy, and his partner, one time a dancer at the Moulin Rouge. As he speaks, I sit and feel these stories fill my legs and hands and I began to gesture in response. We work with some gentle touch, but he wants a firm touch- to feel his edges- as these stories of flight and decent fill the room, moving back and forth between loss and anger... and the remembering and savouring of life force through the felt images that he is calling up.

(Tomos, 13 March 2017, personal correspondence)

It may require a leap of faith in commissioners and health teams to utilise SIMP on their wards. Jarrett observes that the complexity of peoples' needs when ill or in recovery requires the support of a multidisciplinary team- the medical, the therapists, the artists and the volunteers, a team made up of people who understand the health of the bodymind in multiple ways and can envision this. Ultimately, Jarrett points out that the type of work she is remitted to do 'is dependent on how embedded and supported the role of movement and creative arts are in any particular hospital' (Jarrett, 4 May 2017, interview). This was reiterated by all the practitioners who stressed that their work can only grow if they have the support and understanding of the teams on the ward. Rather than being seen as entertainment on the one hand, or another therapeutic intervention on the other, the dance/movement artist on the ward could be seen as an integral member of the care team (APPGAHW 2017: 17), adding to the holistic, person-centred approach considered essential in building a health-based system of care. 


\section{References}

All Party Parliamentary Group for Arts, Health \& Wellbeing (APPGAHW), (July, 2017). 'Creative health: The arts for health and wellbeing report, APPG,

$<$ https://www.artshealthandwellbeing.org.uk/appg-

inquiry/Publications/Creative Health Inquiry Report 2017.pdf > Accessed 18 August 2020.

Bruyneel, Anne-Violette (2019) 'Effects of Dance Activities on Patients With Chronic Pathologies: Scoping Review', Heliyon; 5, 7: 02104.

Carel, Havi (2008), Illness: The cry of the flesh, Oxfordshire: Routledge.

Carel, Havi (2012), 'Phenomenology as a Resource for Patients', The Journal of Medicine and Philosophy: A Forum for Bioethics and Philosophy of Medicine, 37:2, pp. 96-113.

Carel, Havi (2013), 'Bodily Doubt', Journal of Consciousness Studies, 20:7-8, pp. 178-197.

Collinson, Penny \& Herd, Nicola (July, 2020), 'Embodying Health: A review of the work of dance and somatic practitioners working in NHS hospitals', http://clok.uclan.ac.uk/22848/ Accessed 29 September 2020

Connolly, Mary \& Redding, Emma (2010), Dancing towards well-being in the third age: Literature review on the impact of dance on health and well-being among older people. London: Trinity Laban Conservatoire for Music and Dance. 
Dahlberg, Karin, Todres, Les \& Galvin, Kathleen (2009), 'Lifeworld-led healthcare is more than patient-led care: an existential view of wellbeing', Medicine, Health care and Philosophy, 12:3, pp. 265-271.

Dowler, Lisa (2013a) 'Improvising on the ward: Exploring somatic dance and potential in paediatric health care', Journal of Applied Arts and Health, 4:2, pp. 163178.

Dowler, Lisa (2013b), 'Invisible duets: multiple modes of documenting the significance of dance to health', in Animated, (People Dancing), https://www.researchgate.net/publication/303738248 Invisible Duets multiple mod es of documenting the significance of dance to health Accessed 17 June 2020.

Dowler, Lisa (2016), 'Can improvised somatic dance reduce acute pain for young people in hospital?', Nursing Children and Young People, 28:9, pp. 20-25.

Draper, Jan (2014), Embodied Practice: Rediscovering the 'heart' of nursing, Journal of Advanced Nursing, 70:10, 2235-2244.

Eddy, Martha (2016), Mindful Movement: The Evolution of the Somatic Arts and Conscious Action, Bristol, UK: Intellect Books.

Erskine, Richard (2018), Relational Patterns, Therapeutic Presence: Concepts and Practice of Integrative Psychotherapy, Oxon, UK: Routledge.

Galvin, Kathleen and Todres, Les (2013), Caring and Well-Being: A Lifeworld Approach, Abingdon, UK: Routledge. 
Gersten Roberts, June (2017) 'Writing Body Stories', in V. Karkou, S. Oliver and S. Lycouris (eds), The Oxford Handbook of Dance and Wellbeing, New York: Oxford University Press, pp. 349-368.

Hanna, Thomas (1976), 'The Field of Somatics', Somatics: Magazine-Journal of the Bodily Arts and Sciences, 1:1, pp. 30-34.

Hanna, Thomas (1979), The Body of Life: Creating new pathways for sensory awareness and fluid movement, New York: Alfred A. Knopf.

Heath, Iona (2017), 'The missing person: The outcome of the rule-based totalitarianism of too much contemporary healthcare', Patient Education and Counselling, 100:11, pp.1969-1974.

Heath, Iona (2012), 'The art of doing nothing', European Journal of General Practice, 18:4, pp. 242-246.

Howard, Stella (2020), zoom interview with P. Collinson, 25 February.

Jarrett, Lucinda (2017), talking interview with P. Collinson, 4 May.

Jarrett, Lucinda (2019), 'Stroke Odysseys: performance arts after stroke, a service innovation for neurological rehabilitation', https://www.rosettalife.org/wpcontent/uploads/2019/02/BJNN-on-Stroke-Odysseys.pdf Accessed 29 September 2020.

Johnson, Don, Hanlon (1992), Body: Recovering our sensual wisdom, California: North Atlantic Books. 
Johnson, Don, Hanlon (1995), Bone, Breath, \& Gesture: Practices of Embodiment, California: North Atlantic Books.

Mullan, Kelly, Jean (2014), 'Somatics: Investigating the common ground of western body-mind disciplines', Body, Movement and Dance in Psychotherapy, 9:4, pp. 253265.

Payne, Helen (2017), 'The BodyMind Approach: Supporting the Wellbeing of Patients with Chronic Medically Unexplained Symptoms in Primary Healthcare in England', in V. Karkou, S. Oliver, and S. Lycouris (eds), The Oxford Handbook of Dance and Wellbeing, New York: Oxford University Press, pp. 769-788.

Pereira-Stubbs, Filipa (2017) 'Moving from Problem to Potential Dance and Wellness in the US', https://www.wcmt.org.uk/sites/default/files/report-documents/PereiraStubbs\%20F\%20Report\%202014.pdf Accessed 18 June 2020.

Pereira-Stubbs, Filipa (2020) zoom interview with P. Collinson, 4 March.

Sakalys, Jurate, A (2006), 'Bringing bodies back in: Embodiment and caring science', International Journal for Human Caring,10:3, pp. 17-21.

Tomos, Cai (2017), Personal correspondence with P. Collinson, 13 March.

Tomos, Cai (2018), zoom interview with P. Collinson, 28 March.

Tomos, Cai (2020), zoom interview with P. Collinson, 16 January.

Tufnell, Miranda (2000), 'Beneath Our Words', in P. Greenland (ed.), What dancers do that other health workers don't, Leeds: JABADAO. 
Tufnell, Miranda (2017), When I Open my Eyes: Dance, Health, Imagination, Binstead, UK: Dance Books.

World Health Organisation (2015), 'Beyond bias: exploring the cultural contexts of health and well-being measurement', Cultural Contexts of Health and Well-being, 1, vi + 27 pages, https://www.euro.who.int/ data/assets/pdf file/0008/284903/Culturalcontexts-health.pdf Accessed 29 September 2020.

World Health Organization Regional Office for Europe, (2013), Health 2020: A European Policy Framework and Strategy for the 21st century. Copenhagen: WHO Regional Office in Europe, https://www.euro.who.int/en/publications/abstracts/health2020.-a-european-policy-framework-and-strategy-for-the-21st-century-2013 Accessed 17 June 2020.

${ }^{\text {i }}$ SIMP is an acronym I'm using for somatic-informed movement practice, as far as I am aware this is not widely used. 